\title{
Libro interactivo para la enseñanza de la lengua Mazateca de Huautla de Jiménez, Oaxaca
}

\section{Interactive book for teaching the Mazatec language of Huautla de Jiménez, Oaxaca}

\author{
ARMAS-GARCÍA, Eduardo $\dagger$, SABINO-MOXO, Beatriz Adriana* y MARQUEZ-DOMINGUEZ, \\ José Alberto
}

Universidad de la Cañada

ID 1erAutor: Eduardo, Armas-García / ORC ID: 0000-0003-3470-3436, CVU CONACYT ID: 999899

ID 1 ${ }^{\mathrm{er}}$ Coautor: Beatriz Adriana, Sabino-Moxo / ORC ID: 0000-0002-8577-494X, CVU CONACYT ID: 210495

ID $2^{\text {do } C o a u t o r: ~ J o s e ́ ~ A l b e r t o, ~ M a ́ r q u e z-D o m i ́ n g u e z ~ / ~ O R C ~ I D: ~ 0000-0003-2552-2289, ~ C V U ~ C O N A C Y T ~ I D: ~} 210472$

DOI: $10.35429 / J T A E .2019 .9 .3 .27 .34$

Recibido: 30 de Junio, 2019; Aceptado 30 de Septiembre 2019

\begin{abstract}
Resumen
Las lenguas maternas son consideradas como parte del patrimonio cultural de la humanidad, por tal motivo es importante trabajar en su rescate y conservación. En este trabajo se presenta el diseño e implementación de un libro interactivo usando realidad aumentada, mismo que contiene texto en español y en lengua mazateca variante de Huautla de Jiménez, Oaxaca; este material lo emplean profesores de la escuela primaria bilingüe Ing. Jorge L. Tamayo y quienes aportaron retroalimentación para su desarrollo, los temas que se incluyen hacen referencia a la familia y sus actividades en la comunidad, la comida y los animales. La implementación de este recurso se realizó con Vuforia y Unity 3D y la metodología UCD, su funcionamiento consiste en que el usuario coloca la cámara de su dispositivo móvil sobre una imagen del libro, la aplicación la detecta e identifica y despliega objetos $3 \mathrm{D}$ y reproduce el audio de la pronunciación en mazateco del texto asociado a las imágenes. Las pruebas reflejaron un $100 \%$ de efectividad, un 9.5 de aceptación, hubo en promedio 5 segundos de adelanto al tiempo estimado para la realización de las tareas.
\end{abstract}

Realidad aumentada, Usabilidad, Lenguas maternas

\begin{abstract}
Native languages are part of the cultural heritage of humanity, for this reason it is important to rescue and conserve them. This paper presents the design and implementation of an interactive book using augmented reality, which contains text in Spanish and in the Mazatec language variant of Huautla de Jiménez, Oaxaca; This material isused by teachers of the bilingual elementary school Ing. Jorge L. Tamayo, who provided feedback to developit, the topics that are included makere ference to the family and their activities in the community, food and animals. The development of this resource was made with Vuforia and Unity 3D and the UCD methodology, for its operation the user puts the camera of his mobile device on the images of the book, the application detects and identifies the marker and displays 3D objects and reproduces the audio of the pronunciation in Mazatec of the text related to the image. For the tests, two usability evaluations were conducted. The tests reported a $100 \%$ effectiveness, a 9.5 acceptance, there was an average of 5 seconds ahead of the estimated time for the completion of tasks.
\end{abstract}

Augmented reality, Usability, Native language

Citación: ARMAS-GARCÍA, Eduardo, SABINO-MOXO, Beatriz Adriana y MARQUEZ-DOMINGUEZ, José Alberto. Libro interactivo para la enseñanza de la lengua Mazateca de Huautla de Jiménez, Oaxaca. Revista de Tecnología y Educación. 2019. 3-9: 27-34

\footnotetext{
* Correspondencia del Autor (Correo electrónico: beatriz_sabino@unca.edu.com))

$\uparrow$ Investigador contribuyendo como primer autor.
} 


\section{Introducción}

Desde hace varios años, la necesidad de preservar las lenguas indígenas ha sido un tema de absoluta seriedad y de incumbencia mundial, sin embargo, a pesar de los esfuerzos y acciones que se han llevado a cabo, el número de hablantes de lenguas maternas sigue disminuyendo. De acuerdo con el INEGI (2015), el porcentaje de la población de 5 años o más que hablan una lengua indígena ha disminuido de $16.0 \%$ (en 1930) a $6.6 \%$ (en el 2015). Oaxaca es el estado que cuenta con más comunidades indígenas a nivel nacional, y en específico, el mazateco, se encuentra en el décimo lugar de las principales lenguas indígenas que se hablan en el país. Dicha lengua es hablada por habitantes de la comunidad de Huautla de Jiménez y pueblos circundantes, según testimonios de profesores y familias de la comunidad, con el paso de los años, el número de personas, principalmente niños que la hablan ha ido disminuyendo.

Mediante el desarrollo de dos herramientas: un libro escrito en mazatecoespañol y una aplicación móvil con realidad aumentada, este trabajo de investigación contribuye con un material didáctico tecnológico para profesores en la enseñanza de la lengua mazateca en primer grado de la escuela primaria bilingüe Ing. Jorge L. Tamayo de Huautla de Jiménez. Además, aporta en la conservación y difusión de una variante del mazateco de la región Cañada del estado de Oaxaca.

\section{Lenguas Maternas y educación}

La educación está relacionada con el desarrollo del ser humano, debido a que permite desplegar las potencialidades, cultivar capacidades, ampliar las opciones de las personas para transformar su entorno y construir con otros la calidad de vida en sociedad (MEPIPS, 2008). Galdames et al. (2006) indica que la educación básica tiene que ser intercultural y bilingüe, debe fomentar el mayor desarrollo $y$ preservación de la cultura y la lengua en los habitantes de todos los pueblos. Estos autores mencionan que los docentes deben recapacitar sobre la importancia de la lengua materna en la enseñanza, algunos beneficios que tiene el sistema de educación bilingüe son:
- Los niños y niñas aprenden mejor cuando utilizan su lengua materna.

- La educación en lengua materna es fundamental para aprender segundas lenguas.

- El bilingüismo otorga los alumnos mayor capacidad para desenvolverse con seguridad en la sociedad haciendo valer sus derechos y necesidades.

- La escolaridad en la lengua materna de los alumnos, junto al aprendizaje del castellano como segunda lengua, permite que éstos alcancen mejores resultados en todas las materias del currículum.

- La educación en lengua materna es un derecho humano.

Por su parte, la UNESCO (2003) propone cinco ejes sobre los cuales se pueden desarrollar acciones para la recuperación y revitalización de las lenguas, los cuales son:

- La formación lingüística y pedagógica básica.

- El desarrollo sostenible de la alfabetización y de las capacidades locales de documentación.

- $\quad$ El fomento y desarrollo de una política lingüística nacional.

- $\quad$ El fomento y desarrollo de una política educativa.

- La mejora de las condiciones de vida y el respeto a los derechos humanos de las comunidades de hablantes.

En la literatura se encuentran diferentes herramientas de apoyo a la preservación de lenguas maternas, tales como aplicación web para el aprendizaje de la lectoescritura del Chinanteco-Español en el municipio de Petlapa (Servín-Juárez, Ozuna-Gabriel ， 2016); aplicación web para escritura y pronunciación le la lengua Zapoteca (Pacheco et al., 2011); Sistema de aprendizaje de lenguas maternas (Valdez et al., 2016); Software para fortalecer la lectura y escritura de la lengua Tének (Hernández, 2017); Aplicación móvil para el aprendizaje de la lengua Náhuatl (Mirón et al., 2017). 


\section{Metodología}

El proceso se dividió en dos metodologías, la primera en el diseño del libro en lengua mazateca y español con imágenes ilustrativas; y la segunda se empleó para el desarrollo de la aplicación móvil con realidad aumentada.

\section{Metodología para el diseño del libro}

En la Figura 1, se observa el proceso realizado para obtener el diseño del libro como producto.

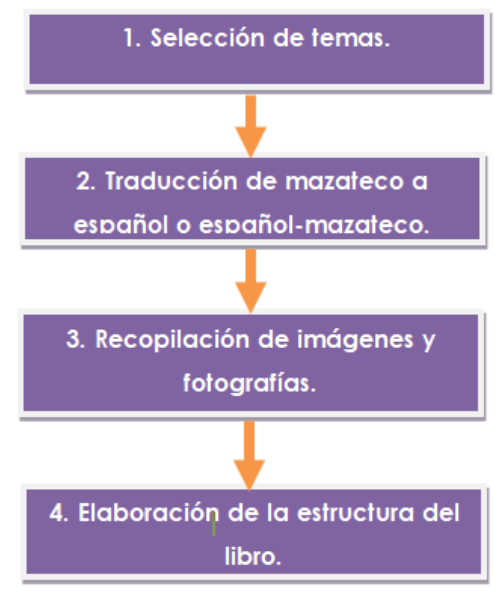

Figura 1 Metodología para el diseño del libro Fuente: Elaboración Propia

Selección de temas. Se acudió a la escuela primaria Ing. Jorge L. Tamayo para platicar con los profesores acerca de los temas que proponían para ser incluidos en el libro interactivo. Al final de la sesión, se determinó que en la propuesta se incluirían tres principales temas:

1. La familia en Huautla y sus actividades.

2. Los animales.

3. Los alimentos.

Traducción de mazateco a español y español a mazateco. La traducción se realizó en español-mazateco o mazateco-español, debido a que en ocasiones el texto base se encontraba en una sola lengua, por lo que fue necesario obtenerla en la segunda. Además, con el apoyo de los profesores de la primaria bilingüe se consiguieron realizar grabaciones del audio de la información.

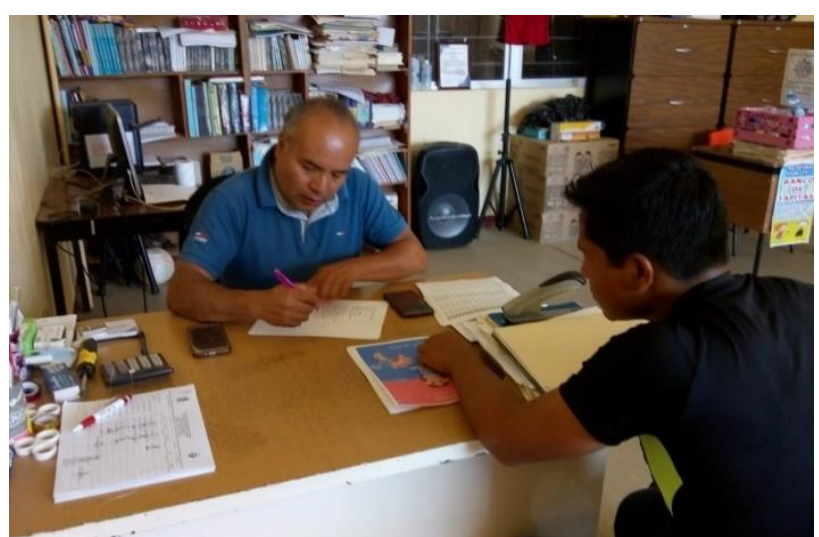

Figura 2 Realización de traducciones con profesor de la escuela primaria bilingüe Ing. Jorge L. Tamayo.

Recopilación de fotografías. Las fotografías fueron capturadas en la comunidad de Huautla de Jiménez, Oaxaca, en ellas se plasman las actividades que se realizan en casa, campo, comercio, lugares de la comunidad, entre otros.

Elaboración de la estructura del libro. Se acudió a la escuela primaria bilingüe Ing. Jorge L. Tamayo para recibir una orientación de la distribución del contenido del material. Los profesores mencionaron que es conveniente que la estructura de este libro sea semejante al que utilizan actualmente para enseñar mazateco, de esta forma se aprovecha un esquema que los niños ya conocen y además se incluyen recursos digitales (audios, imágenes, modelos 3D, etc.). Cabe mencionar que este material lleva por nombre Xon Chine, que en mazateco significa "libro de conocimiento".
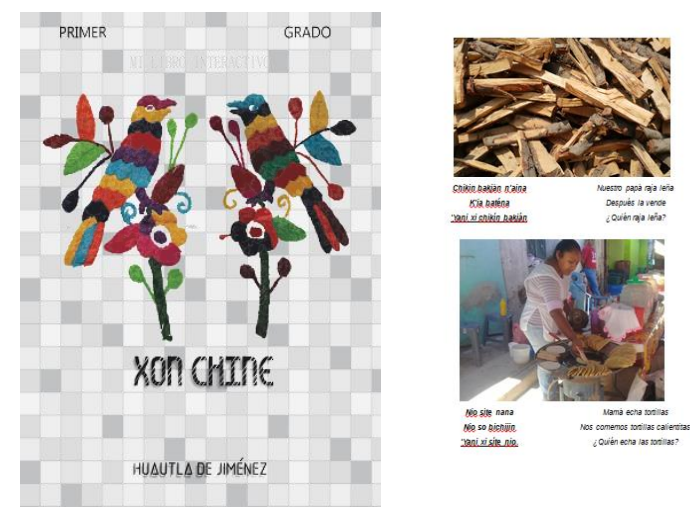

Figura 3 Vista la portada y de una página del libro

\section{Metodología para el desarrollo de la aplicación}

La metodología del Diseño Centrado en el Usuario (DCU) sigue un ciclo iterativo, y comprende cuatro etapas fundamentales: estudio, diseño, construcción y evaluación (Norman y Draper al, 1986).

ARMAS-GARCÍA, Eduardo, SABINO-MOXO, Beatriz Adriana y MARQUEZ-DOMINGUEZ, José Alberto. Libro interactivo para la enseñanza de la lengua Mazateca de Huautla de Jiménez, Oaxaca. Revista de Tecnología y Educación. 2019 
Se caracteriza en que el usuario es considerado en el diseño del producto final (Figura 4).

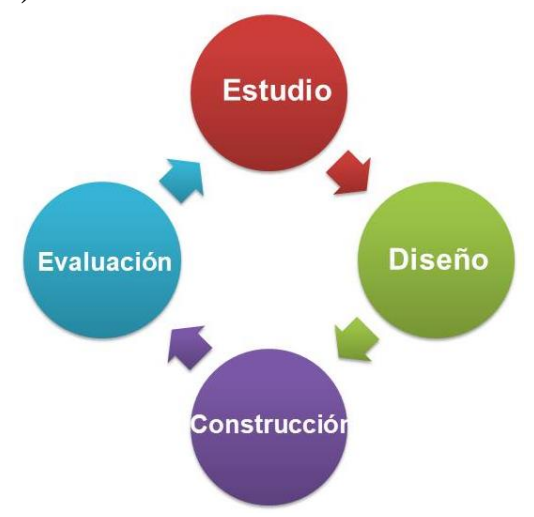

Figura 4 Etapas de la Metodología UCD

Fase de estudio. Se determinaron diferentes aspectos del funcionamiento de la aplicación, como los siguientes:

Alcance y usuarios. La aplicación tiene propósito ser una herramienta de apoyo para la enseñanza dela lengua mazateca en primer grado de la primaria bilingüe "Ing. Jorge L. Tamayo", de la comunidad de Huautla de Jiménez, Oaxaca.Los usuarios de la aplicación son los profesores que imparten en este grado.

Descripción general y factibilidad. Actualmente los profesores cuentan con dispositivos móviles, por lo que el uso de la aplicación no está limitado, los requisitos de la aplicación son los siguientes:

- Dispositivo con Android 4.1 o superior.

- Bocinas funcionales (internas 0 externas).

- Cámara trasera.

- $350 \mathrm{MB}$ libres de espacio de almacenamiento interno.

- $\quad$ GB de memoria RAM.

- Pantalla en buenas condiciones.
Funciones de la aplicación. Servirá como mediador de la interacción entre el libro diseñado y el usuario mediante el reconocimiento de imágenes específicas (marcadores). Al iniciar la aplicación, ésta abrirá la cámara del dispositivo, y en el momento de focalizar y reconocer alguna imagen, se muestra en pantalla un modelo 3D y se reproduce el audio en mazateco del contenido que se está trabajando.

Restricciones. Algunas restricciones establecidas son:

- La aplicación funcionará bajo la plataforma Android (versión 4.1 en adelante).

- La aplicación funciona únicamente con las imágenes incluidas en el libro Xon Chine.

- Los lenguajes que en su defecto serán utilizados son los soportados por el editor Unity.

- La aplicación será utilizada por profesores y en su defecto por alumnos siempre y cuando sean supervisados por sus tutores.

Requerimientos funcionales y no funcionales. Los funcionales son:

- Reconocimiento de imágenes.

- Combinación de lo real con lo virtual.

- Reproducción de recursos multimedia.

Los no funcionales contemplados son:

- Tiempo de respuesta.

- Disponibilidad.

- Portabilidad.

- Mantenimiento.

Fase de diseño. Mediante diferentes tareas, se definieron algunos aspectos de diseño junto con los usuarios.

Prototipos de baja fidelidad. Se realizaron prototipos de baja fidelidad en donde se ilustra el flujo de la aplicación desde que inicia hasta que despliega los elementos multimedia que (Figura 5). 


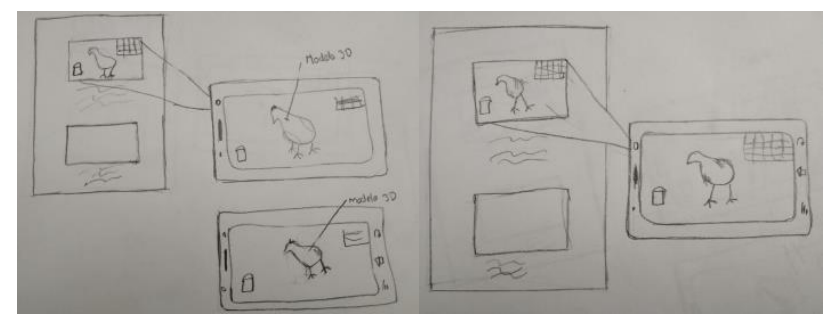

Figura 5 Prototipos de baja fidelidad Fuente: Elaboración Propia

Entrada y salida de datos. Como datos de entrada se consideran aquellos que el usuario ayudará a captar a la aplicación mediante su interacción con ella, estos son las imágenes incluidas en el libro Xon Chine. Como datos de salida, se tienen los modelos $3 \mathrm{D}$ que la aplicación mostrará al reconocer las imágenes enfocadas por el usuario, así como el audio de la pronunciación en mazateco que será reproducido.

\section{Tipos de datos y flujo de aplicación}

Las imágenes manejadas serían en formato jpg.

Los audios utilizados serán archivos mp3.

- $\quad$ Los modelos 3D tentativamente tendrían la extensión obj.

En la Figura 6 y 7, se representa el flujo básico de la aplicación definido en esta etapa.

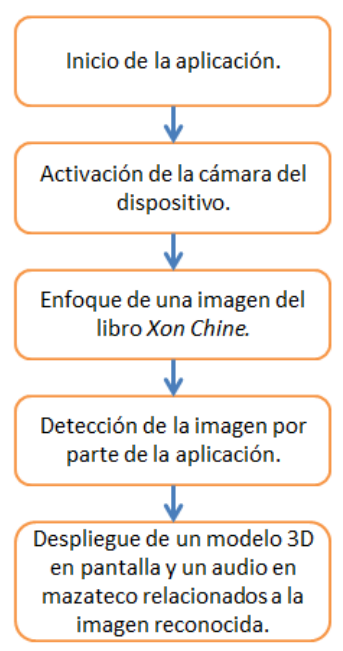

Figura 6 Flujo básico del funcionamiento de la aplicación

Fuente: Elaboración Propia

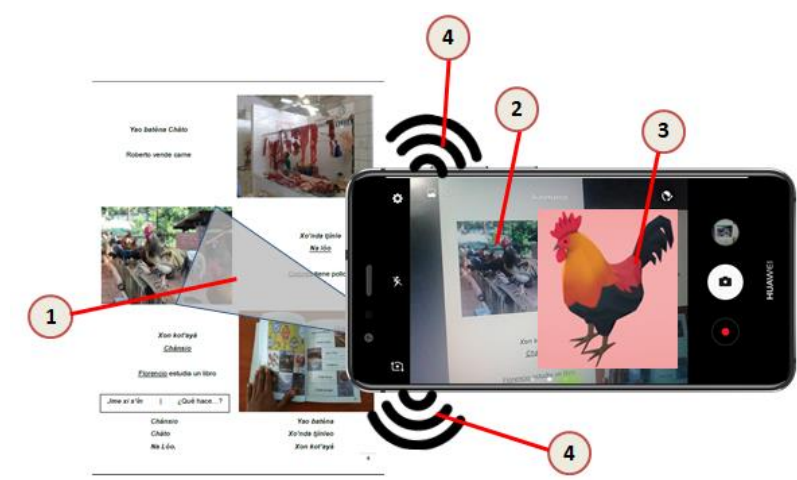

Figura 7 Proceso de la aplicación Fuente: Elaboración Propia

En la Figura 7, se observa el funcionamiento general de la aplicación, primero (1), el usuario enfoca una imagen del libro Xon Chine, en el paso (2), la aplicación detecta la imagen que se trata y (3) despliega un modelo 3D asociado a la imagen detectada, por último (4), se reproduce un audio con la pronunciación en mazateco escrita al pie de la imagen.

\section{Fase de Construcción.}

Se obtuvo un producto funcional de la herramienta, basado en la etapa de estudio y diseño, donde se define la estructura del sistema y requerimientos a cubrir entre otros.

Herramientas de desarrollo. Luego de contar con el análisis y diseño de la aplicación, se procedió a la etapa de implementación para obtener un producto para el usuario, para esto, las herramientas de software utilizadas fueron:

\section{- Unity 3D, motor para el desarrollo juegos y aplicaciones. \\ - Vuforia, para las funciones de empleo de la realidad aumentada, las cuales mediante paquetes pueden ser importadas fácilmente en el proyecto de Unity. \\ Poly, una plataforma de Google de objetos digitales en 3D bajo licencia Remixing y Creative Commons.}

Se utilizan funciones de Vuforia para reconocer las imágenes del libro Xon Chine, posteriormente se descargar como paquete y se importar en un proyecto de Unity(Figura 8). 


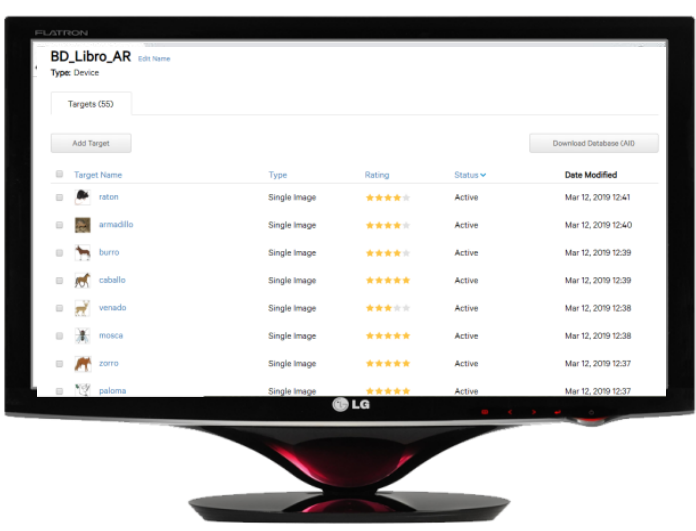

Figura 8 Base de datos de imágenes creada en Vuforia del libro Xon Chine, para su reconocimiento en la aplicación

Fuente: Elaboración Propia

Cada una de las imágenes incorporadas en Vuforia recibe una calificación en estrellas respecto a la facilidad que tendrá de ser reconocida.

A continuación, se obtuvieron los modelos 3D relacionados a las imágenes mediante el repositorio Poly de Google. Finalmente, se empleó Unity para conjuntarlos y obtener un producto funcional (Figura 9).

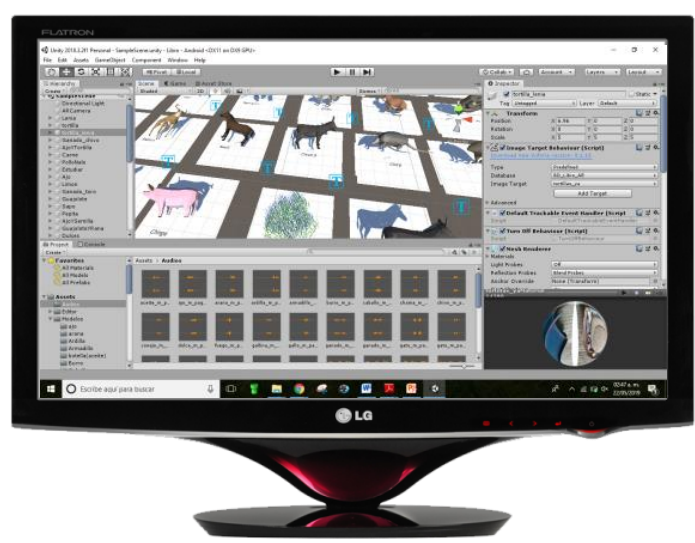

Figura 9. Captura de pantalla del Unity durante el proceso de desarrollo

Fuente: Elaboración Propia

En la Figura 10, se muestra una captura de la aplicación en funcionamiento.

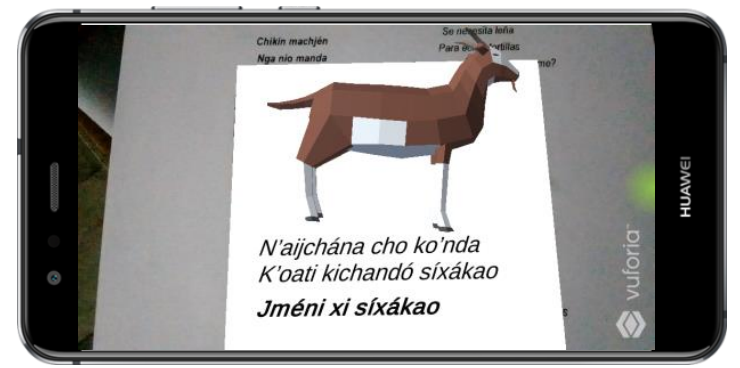

Figura 10 Captura de pantalla de la aplicación en funcionamiento

Fuente: Elaboración Propia
Fase de Evaluación. Para la evaluación del software, se realizaron dos pruebas de usabilidad con usuarios de la aplicación.

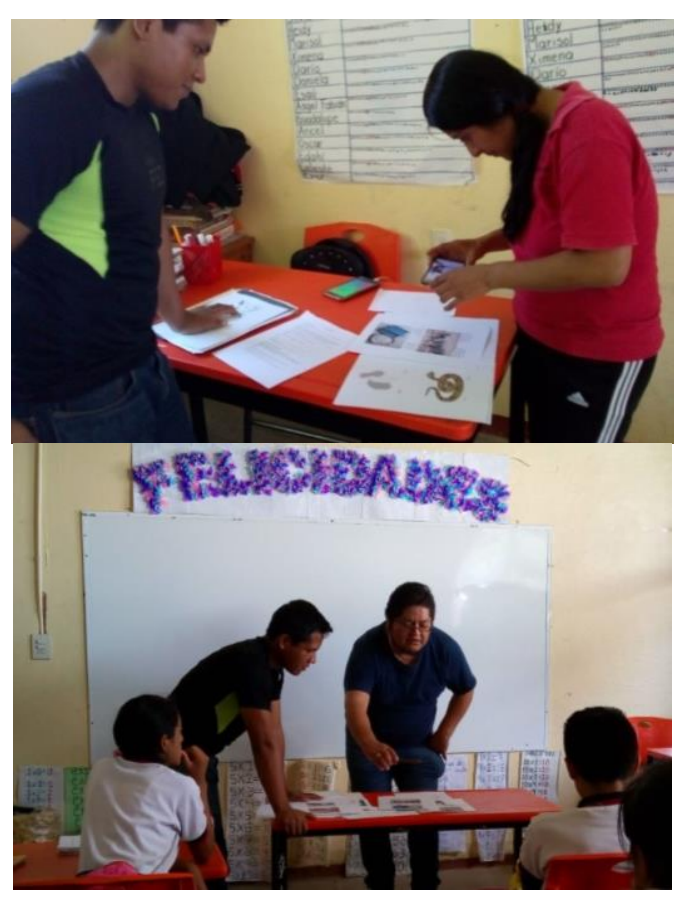

Figura 11 Realización de pruebas de usabilidad con usuarios de la aplicación: profesores

Fuente: Elaboración Propia

Para esto se contó con la participación 9 usuarios en la primera prueba y 3 en la segunda. Las métricas que se evaluaron fueron: efectividad, satisfacción y eficiencia.

- Efectividad, representa al número de tareas completadas con éxito.

- Satisfacción, se refiere a ¿Cómo califican los usuarios el sistema?

- Eficiencia, mide el tiempo necesario para realizar cada tarea.

Las tareas requeridas en las pruebas se describen enseguida:

- Colocar la cámara del dispositivo y desplegar un objeto 3D y escuchar sonido.

- $\quad$ Reproducir sonido nuevamente.

- $\quad$ Escribir la palabra que escucha.

\section{Resultados}

La primera prueba reflejó un porcentaje de $96.3 \%$ en cuanto a efectividad, un $88 \%$ en satisfacción, y la eficiencia tuvo en promedio 32 segundos de retraso respecto al tiempo estimado para la realización de las tareas. 
La segunda reflejó mejores resultados, con un $100 \%$ de efectividad, un 9.5 de satisfacción, además, hubo en promedio 5 segundos de adelanto al tiempo estimado para la realización de las tareas.

Dada la implementación de la metodología para el desarrollo del libro, y de la aplicación, se obtuvieron como producto ambos elementos de la propuesta: un libro en español y mazateco (Xon Chine) y una aplicación con realidad aumentada que lo complementa.

\section{Agradecimientos}

El presente trabajo ha podido ser realizado gracias a la participación directa o indirecta de diferentes personas.

Se agradece al profesor Reynaldo Villegas Carrera, director de la escuela primaria bilingüe Ing. Jorge L. Tamayo y a los profesores por su gran ayuda y participación en el surgimiento de la propuesta, integración y traducción de los contenidos del presente trabajo.

Se agradece a la C. Elvia Cerqueda Delgado, quien tuvo a bien prestar su voz para la realización de algunas grabaciones y de textos en mazateco.

Se agradece al C. Francisco Javier Valencia Martínez, por el aporte de sus conocimientos para la traducción y grabación de la pronunciación de diferentes textos en mazateco. Se agradece a PRODEP por la financiación para la ejecución del proyecto de investigación.

\section{Conclusiones}

Con el desarrollo de este, se aprovechan las tecnologías para atacar una problemática de la región, y dado que la tecnología destinada a la enseñanza de las lenguas maternas y en específico a la enseñanza del mazateco es poca o nula, resulta ser un concepto innovador y atrayente para los profesores. Al final del proceso, se obtuvo un prototipo (aplicación) funcional y usable para los profesores de primer grado de la escuela primaria bilinguie Ing. Jorge L. Tamayo, debido a que en el área de HCI, se busca que las aplicaciones se desarrollen de acuerdo al contexto y necesidades de los usuarios.
Dicho prototipo tuvo buenas calificaciones de usabilidad durante el proceso de desarrollo, factor sobre el cual influyó la metodología utilizada, ya que los usuarios estaban previamente familiarizados con el funcionamiento y uso de la aplicación, además de que se atendieron sus comentarios y observaciones después de cada evaluación.

\section{Referencias}

Hernández F., (2017). Impacto del software educativo "in ajum ani in dhuchum tének" (leo $y$ escribo en tének). Congreso Nacional de Investigación Educativa, San Luis Potosí.

INEGI. Instituto nacional de estadística y geografía. (2015). Lengua indígena. Disponible en: http://www.beta.inegi.org.mx/temas/lengua/ INEGI- Instituto nacional de estadística y geografía. 2016. Disponible en: http://www.inegi.org.mx/saladeprensa/aproposit o/2016/indigenas2016_0.pdf

Galdames V., Walqui A. yGustafson B. (2006). Enseñanza de Lengua Indígena como Lengua Materna. México: Coordinación General de Educación Intercultural y Bilingüe.

Mirón M., Jiménez D., Juárez J. y Angheven J. (2017). Desarrollo de aplicación móvil como herramienta de aprendizaje para Náhuatl en la variante Orizabese. Revista de Sistemas Computacionales y TIC'S 2017, 3-9: 7-13.

Movimiento de Educación Popular Integral y Promoción Social (2008). Una mejor educación para una mejor sociedad. Propuestas para el diálogo y la transformación educativa en América Latina y el Caribe. España: Iarricio Artes Gráficas.

Norman, D. y Draper, S. (1986). User Centered System Design: New Perspectives on HumanComputer Interaction. L. Erlbaum Associates: USA.

Pacheco G., Cárdenas L., y Ruiz F. (2011). Enseñanza de la lengua Zapoteca, mediante el uso de tecnologías de software libre. Temas de Ciencia y Tecnología, vol. 15, pp 37-40.

Servín-Juárez F., Ozuna-Gabriel P. (2016). Software para la Lectoescritura de la Lengua Chinanteca. Salud y Administración. Vol. 3 (8). Pp. 49-58. 
UNESCO (2003). Vitalidad y peligro de desaparición de las lenguas. Disponible en: http://www.unesco.org/new/fileadmin/MULTI MEDIA/HQ/CLT/pdf/LVE_Spanish_EDITED $\% 20 \mathrm{FOR} \% 20 \mathrm{PUBLICATION} . \mathrm{pdf}$ 